\title{
A field effort to capture critically endangered vaquitas Phocoena sinus for protection from entanglement in illegal gillnets
}

L. Rojas-Bracho ${ }^{1}$, F. M. D. Gulland ${ }^{2, *}$, C. R. Smith ${ }^{3}$, B. Taylor ${ }^{4}$, R. S. Wells ${ }^{5}$, P. O. Thomas ${ }^{6}$, B. Bauer ${ }^{3}$, M. P. Heide-Jørgensen ${ }^{7}$, J. Teilmann $^{8}$, R. Dietz ${ }^{8}$, J. D. Balle ${ }^{8}$, M. V. Jensen ${ }^{8}$, M. H. S. Sinding ${ }^{7}$, A. Jaramillo-Legorreta ${ }^{9}$, G. Abel ${ }^{3}$, A. J. Read $^{10}$, A. J. Westgate ${ }^{11}$, K. Colegrove ${ }^{12}$, F. Gomez ${ }^{3}$, K. Martz ${ }^{3}$, R. Rebolledo ${ }^{3}$, S. Ridgway ${ }^{3,13}$, T. Rowles $^{14}$, C. E. van Elk ${ }^{15}$, J. Boehm², G. Cardenas-Hinojosa ${ }^{9,21}$, R. Constandse ${ }^{16}$, E. Nieto-Garcia ${ }^{9}$, W. Phillips ${ }^{16}$, D. Sabio ${ }^{17}$, R. Sanchez ${ }^{16}$, J. Sweeney ${ }^{18}$, F. Townsend ${ }^{19}$, J. Vivanco ${ }^{20}$, J. C. Vivanco $^{20}{ }^{2}$ S. Walker ${ }^{3}$

${ }^{1}$ Comisión Nacional de Áreas Naturales Protegidas/SEMARNAT, Ensenada, BC 22860, Mexico

${ }^{2}$ The Marine Mammal Center, Sausalito, CA 94965, USA

Addresses for other authors are given in the Supplement at www.int-res.com/articles/suppl/n038p011_supp.pdf

\begin{abstract}
In 2017 an emergency field effort was undertaken in an attempt to prevent the extinction of the world's most endangered marine mammal, the vaquita Phocoena sinus. The rescue effort involved 90 experts from 9 countries and cost US\$ 5 million. Following a long decline due to entanglement in legal gillnet fisheries, the vaquita population had fallen from more than 200 to fewer than 30 individuals from 2008 to 2016, due to entanglement in an illegal gillnet fishery that supplies swim bladders of the endangered totoaba Totoaba macdonaldi to Chinese black markets. An emergency ban of gillnets and increased enforcement failed to slow the decline, triggering an emergency effort to catch vaquitas and place them under protection in captivity. Two animals were targeted and captured using light gill nets; a juvenile was released $4 \mathrm{~h}$ later because it appeared stressed, and an adult female died of capture myopathy. The program was suspended because of the risk of additional mortalities to the population. The lack of success in capturing vaquitas for temporary protection emphasizes the need to improve our understanding of the effects of chase, capture, handling and enclosure on cetaceans, and to consider intervention before populations reach critically low levels, when there is sufficient time to use phased, precautionary approaches. Furthermore, conservation approaches focused on single species must be integrated into broader efforts to conserve ecosystems and involve the human communities that depend on them.
\end{abstract}

KEY WORDS: Vaquita $\cdot$ Cetacean conservation $\cdot$ Porpoise $\cdot$ Capture myopathy $\cdot$ Ex situ

\section{INTRODUCTION}

Here we describe 'VaquitaCPR' (CPR: conservation, protection, recovery), a project intended to save the vaquita Phocoena sinus from extinction by temporarily removing individuals from adverse in situ conditions and placing them into emergency care. The vaquita,

${ }^{*}$ Corresponding author: gullandf@tmmc.org first described in 1958 (Norris \& McFarland 1958), is a species of porpoise endemic to the Upper Gulf of California, México. Since its discovery, the population has declined at an increasing rate: estimated population size was 567 in 1997, 245 in 2008, 60 in 2015, and 30 in 2016 (Thomas et al. 2017). Between 1997 and 2008 the population decline of $7-8 \% \mathrm{yr}^{-1}$ was primarily due to

(C) The authors, and outside the USA, the US Government 2019. Open Access under Creative Commons by Attribution Licence. Use, distribution and reproduction are unrestricted. Authors and original publication must be credited.

Publisher: Inter-Research · www.int-res.com 
mortality in gillnets set for shrimp and finfish (RojasBracho \& Reeves 2013). From 2011 to 2016, the rate of decline increased to $39 \% \mathrm{yr}^{-1}$ due to entanglement in illegal gillnets set for totoaba Totoaba macdonaldi. This illegal fishery was driven by the lucrative black market for swim bladders of the endangered totoaba in Hong Kong and China, which enabled fishers to receive up to US\$ $20000 \mathrm{~kg}^{-1}$ of swim bladder, and as much as US\$ 116000 in 1 day (Crosta \& Sutherland 2017). The increase in the black market for totoaba swim bladders is relatively recent and has had dramatic effects on vaquitas, although mortality of vaquitas in gillnets set for totoaba is not a new phenomenon. In the 1960s, vaquitas were described as difficult to find and the population was believed to be in decline, due to entanglement in the totoaba gillnet fishery, with mortalities on the order of 10-100 vaquitas $\mathrm{yr}^{-1}$ (Norris \& Prescott 1961, Brownell 1976). Despite closure of the fishery in 1975, Vidal (1995) reported that at least $65 \%$ of 128 dead vaquitas found between 1985 and 1992 had died in totoaba gillnets.

The International Committee for the Recovery of Vaquita (CIRVA) was established in 1997 to advise the Government of México (GoM) on conservation actions for vaquitas. For 20 yr CIRVA has recommended reducing vaquita bycatch to zero by eliminating gillnets and developing alternative fisheries and socio-economic alternatives for affected fishers. In addition, CIRVA recommended increased enforcement and population monitoring using passive acoustics (CIRVA Reports 2-10, IUCN Cetacean Specialist Group webpage at www.iucn-csg.org). To reduce vaquita entanglement in legal fisheries for shrimp and finfish, a vaquita refuge was established in 2005 in which gillnets were prohibited. Approximately half of the vaquitas detected in 2008 visual and acoustic surveys were found in the refuge area, which was partially enforced from 2008 onwards (Fig. 1). A variety of other conservation measures were implemented by the GoM (CIRVA-9 2017).

An improved passive acoustic monitoring program was established in 2011 to quantify anticipated posi- tive results of these conservation measures. Instead, in 2014 the acoustic program revealed a catastrophic vaquita population decline. This prompted a temporary 2-yr ban of most gillnet fisheries in 2015, which was made permanent in 2017 (Rojas-Bracho \& Reeves 2013, International Whaling Commission 2018). During this period, affected fishers were compensated, the Mexican Navy assumed the responsibility of enforcing the measures, and work on the development of alternative fishing methods was accelerated. Despite these actions, the exorbitant revenues derived from totoaba swim bladders incentivized continued illegal gillnet fishing, and the population decline continued unabated (JaramilloLegorreta et al. 2017, Thomas et al. 2017). In a single totoaba fishing season, between December 2016 and May 2017, 150 illegal totoaba nets (large mesh gillnets designed to catch totoaba) were retrieved from the vaquitas' range (CIRVA-9 2017). After consider-

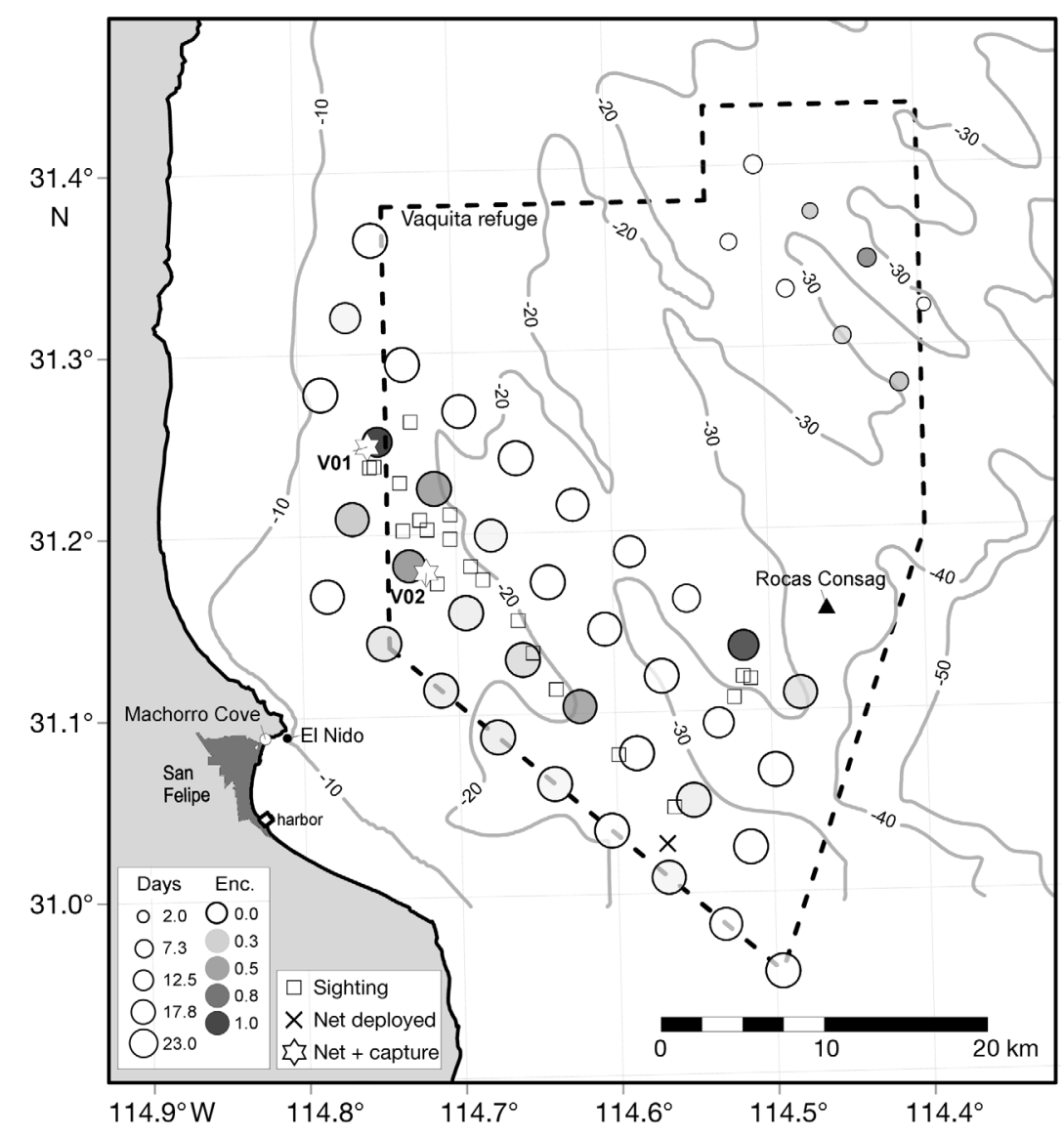

Fig. 1. Upper Gulf of California including the vaquita refuge partially enforced from 2008 and onwards with signatures on the passive acoustic monitoring stations (C-PODs) and observations and capture sites from the operation from 13 October to 4 November 2017. Ex situ facilities were situated at Machorro Cove and El Nido. Days: number of whole days $(24 \mathrm{~h})$ sampled. Enc.: acoustic encounter rate. The dashed line indicates the vaquita refuge area 
ing these developments, in 2017 CIRVA concluded that 'the only hope for the survival of the species in the short term is to capture vaquitas and bring them into human care' (CIRVA-9 2017, p. 4). This report recognized that 'the risks of capture and captive management are high, but these are greatly outweighed by the risk of entanglement in illegal gillnets in the wild.'

Ex situ conservation strategies, such as temporary housing for protection and captive breeding for reintroduction, can be useful tools to prevent extinction, although there are concerns over the value of such efforts (Price 1986, Martin et al. 2012, Ralls \& Ballou 2013). Captive breeding with subsequent release into the wild has not been used in prior conservation efforts with small cetaceans, despite captive breeding success with some related species (e.g. harbor porpoise Phocoena phocoena, Yangtze finless porpoise Neophocaena asiaeorientalis asiaeorientalis, bottlenose dolphins Tursiops truncatus and T. aduncus; Wang et al. 2009, 2015, Curry et al. 2013). This is due in part to the difficulty with initial acclimation of some cetacean species to human care (e.g. Dall's porpoises Phocoenoides dalli, Irrawaddy dolphins Orcaella brevirostris; Reeves \& Mead 1999, Curry et al. 2013); the limited success of breeding some species of cetaceans in captivity; controversy over the utility of the action, and philosophical opposition to keeping cetaceans in captivity (Curry et al. 2013, Butterworth 2017). A major concern in proposing to establish ex situ populations is that these efforts may detract from vital in situ efforts by seeming to provide alternative options for management authorities, or using funds that could be better directed to enhancing in situ actions (Bowkett 2009). Short-term ex situ methods, without captive propagation, have been applied to other marine mammals, with the translocation and/or release of individuals temporarily removed from the wild. For example, human intervention has led to increased survival of endangered Hawaiian monk seals Neomonachus schauinslandi, with as much as a third of the population benefitting from such efforts (Harting et al. 2014, Norris et al. 2017). One major challenge with implementing an ex situ approach with the vaquita is that experience with releasing cetaceans from human care is minimal. A recent review emphasized the challenges of capture, maintenance, and captive reproduction of poorly known small cetaceans: there is a significant body of knowledge with more commonly housed cetaceans such as bottlenose dolphins, but there is much less experience with other species (Curry et al. 2013). Bottlenose dolphins have been released after years, or even birth, in captivity, with mixed success (Gales \& Waples 1993, Wells et al. 1998, 2013). In 2004, international experts recommended translocation of the few remaining baiji Lipotes vexillifer to an established semi-natural reserve, but by the time the effort was initiated, the species had been lost (Braulik et al. 2005).

Over the past decade, techniques for the capture, transport, rehabilitation and release of harbor and finless porpoises have improved considerably. The success rate of rehabilitating stranded or bycaught harbor porpoises has increased markedly (Kastelein et al. 1990, Neimanis et al. 2004, Zagzebski et al. 2006). In the Netherlands, a harbor porpoise rehabilitation program ran from 1967 to 2016, during which 179 porpoises were admitted; 64 of these individuals were released after treatment and 21 were adopted into the permanent collection as they were deemed unfit for release (C. E. van Elk unpubl. data). Despite limited breeding effort with the collection animals, 4 calves were born and successfully reared. Several aquaria in Japan currently house finless porpoises that were caught intentionally, or captured accidentally in fishing nets and subsequently taken into captivity, and in China, a stranded finless porpoise was rehabilitated and released from Beijing Aquarium (Yu et al. 2009). However, the most dramatic and successful use of a protected reserve can be found in the translocation of the Yangtze River finless porpoises into a protected oxbow lake (Wang 2009, International Whaling Commission 2018). The initial net transfer of 19 animals from 1990 to 2004 has now resulted in a breeding population of over 60 animals which represent $6 \%$ of the known population (Mei et al. 2014, Wang 2015). Almost 200 harbor porpoises were handled, tagged and released between 1997 and 2018 in European waters, and only 3 died (J. Teilmann pers. obs.), and 37 harbor porpoises were caught actively in drifting gillnets in Greenlandic and Danish waters with no casualties (van Beest et al. 2018, Nielsen et al. 2018). In the North Sea, harbor porpoises that were accidentally entrapped alive in pound nets have been sampled, tagged, released and tracked. These animals showed indicators of stress (increased respiratory and heart rates, high blood cortisol levels) that varied markedly among the 42 individuals, but no deaths were reported (Eskesen et al. 2009).

Other than 1 live-stranded neonate which died shortly after collection 2 decades ago (see Curry et al. 2013), there were no records of capture, handling or housing vaquitas prior to the initiation of the Vaquita CPR project. Thus, development of an ex situ pro- 
gram faced numerous serious challenges from the start. For example, it was not known whether: (1) it would be possible to find vaquitas, given the severity of population decline, their small size and elusive nature, and the size of the refuge; (2) vaquitas could be captured safely; (3) vaquitas could be transported from a capture site to holding facilities; (4) vaquitas could adapt to holding facilities; (5) vaquitas could be maintained for the time period (likely years) required to clear their habitat from gillnets; (6) vaquitas would breed under human care; or (7) vaquitas could be released successfully after captivity.

Despite these challenges, the proximity of considerable cetacean capture and care resources within $5 \mathrm{~h}$ drive of vaquita habitat made consideration of an ex situ approach feasible, and in 2017 the imminent risk of extinction due to entanglement in totoaba nets was considered higher than the risks to individual vaquitas from capture and placement in protected enclosures. Therefore, under the direction of the Mexican government, a program was initiated to capture vaquitas and place them in a facility in the Upper Gulf of California to protect them from gillnets, with the intent of releasing them once the gillnet threat was eliminated. This paper gives an overview of these efforts.

\section{MATERIALS AND METHODS}

\subsection{Planning}

In proposing an ex situ approach as part of the conservation strategy, it was vital that other conservation actions, particularly elimination of gillnets from the vaquitas' habitat, were not compromised. Plans for VaquitaCPR were developed in parallel with efforts to declare and enforce an expanded ban on the use of gillnets, remove illegal, abandoned, lost and discarded gillnets from the vaquitas' range, develop alternative fishing techniques, and increase awareness of the vaquitas' plight. Planning for the possibility of the use of an ex situ approach was initiated in 2015, 2 yr prior to the recommendation by CIRVA to initiate such a program.

To minimize risks associated with catching, handling and housing vaquitas, a step-wise, precautionary approach was developed in September 2015, with each step of the plan contingent upon the success of previous steps (see Annex 3 of CIRVA-7 2016), and this was presented to CIRVA in May 2016. CIRVA then recommended a site visit to the Upper Gulf of California to assess the feasibility of ex situ conservation actions, and refinement of the objectives of an ex situ conservation strategy. In November 2016, CIRVA recommended starting the ex situ program using a precautionary approach (CIRVA-8 2016), and the GoM requested that planning and fundraising efforts be accelerated and that the multiple steps be compressed into a single field effort. The field program was initiated in October 2017. The plan (www.vaquitacpr.org/vaquitacprconservation-program-plan/) was reviewed by an independent review panel (IRP), which also was charged with review of circumstances around any injury or mortality, and then making a recommendation to the VaquitaCPR program lead, the GoM, and CIRVA, as to whether the project should proceed with or without modification, or be terminated.

The goals of the VaquitaCPR program were to find, catch, and house up to 10 vaquitas in net pens or softsided pools adjacent to the vaquita refuge, and once catch operations and acclimation of vaquitas to human care were successful, build a large sanctuary in the Upper Gulf of California for long-term housing and captive breeding. The ultimate aim of the capture initiative was to preserve the species for future release into a fully protected (i.e. gillnet-free) wild habitat. The first step, requiring the greatest lead time, was construction of appropriate housing facilities. Field efforts to capture vaquitas were expected to be feasible only during very calm seas (Beaufort sea state 0-2), due to the small size and cryptic nature of the animals. Once funding was secured and facilities were available, the earliest period of potential good weather was October 2017. This coincided with the season when vaquita calves would be weaning, so capture of females with neonates would be avoided, as peak birth season is March-May (Hohn et al. 1996).

\subsection{Communications and fundraising}

A fundraising team was charged with raising approximately US\$ 5 million within 6 mo. The team solicited individuals, foundations, associations, and corporations, and resulting support was through 2 primary supporters, the GoM and the Association of Zoos and Aquariums (AZA), through its members (see www.vaquitacpr.org for all supporters). The challenge inherent for this campaign was raising funds for an effort with no proof of concept, on an extremely short timeline. A communications team was also established, led by GoM and VaquitaCPR communications officers. In preparation for field 
efforts, a VaquitaCPR communications plan and a crisis communications plan, a VaquitaCPR website (www.vaquitacpr.org), social media and website content, a VaquitaCPR logo, press releases, talking points, communications and outreach materials, and media agreements were all generated.

\subsection{Facilities}

The land-based vaquita care center was constructed at Machorro Cove, San Felipe, México (Fig. 1). This location was selected because (1) it was one of the few locations near the vaquita refuge that offered protection from some of the strong winds that frequently occur in the area; (2) water quality in the cove was adequate for housing animals (e.g. low coliform counts, appropriate salinity and water temperature); (3) it was near the largest town in the area, San Felipe, facilitating construction, communications, security, and access to supplies and ground and air transportation; and (4) San Felipe has the only harbor near the vaquita refuge with shelter for large and small vessels and a Mexican Navy base suitable for housing US Navy dolphins (see Section 2.4.).

The vaquita care center included a $9.14 \times 36.6 \mathrm{~m}$ reinforced tent (Alaska Structures), equipped with HEPA air filtration and climate control, and 3 pools with water filtration, cooling, and heating systems (Aqua Logic). Two oval $(15 \times 5 \mathrm{~m}) 22500$ gallon ( 85000 l) soft-sided pools (Sofpool) and a rectangular $(9 \times 5 \mathrm{~m}) 15000$ gallon $(\sim 57000 \mathrm{l})$ pool (Splash Pools) were staged on sound-proof flooring. Seawater was pumped in from Machorro Cove. An adjacent building was renovated and outfitted for offices, a laboratory, fish preparation, and cold storage. Additional soft-sided above-ground pools of varying sizes were staged for potential use. A Mexican Navy security outpost was constructed on site with project funding. A private security firm was hired to ensure the safety of animals, personnel, and facilities.

A $40 \mathrm{~m}$ diameter circular anchored sea-pen with 2 enclosed smaller pens ( $6 \mathrm{~m}$ and $9 \mathrm{~m}$ diameter) was located just offshore of the vaquita care center. Originally built to house bluefin tuna Thunnus orientalis, the pen was towed $2490 \mathrm{~km}$ from Ensenada, México, and modified for vaquitas. The sea-pen walls were constructed with small-mesh net $(5.7 \mathrm{~cm}$ stretch knotless nylon net dipped in Flexabar paint) and the net was stretched between rigid, hollow pipes at the top (surface) and bottom (sub-surface) of the pens to minimize risk of entanglement by eliminating billowing. The depth of the enclosure could be controlled by raising and lowering the bottom perimeter ring, with a minimum depth of $1.5 \mathrm{~m}$ in the 2 smaller seapens and a minimum depth of $4 \mathrm{~m}$ in the $40 \mathrm{~m}$ seapen. The $40 \mathrm{~m}$ diameter sea-pen was constructed to be modular and the smaller internal sea-pens were removable, so that animals could be moved between pools as appropriate. Small fish and invertebrates were able to swim in and out of the pens. Above water, a soft net fence was secured to the perimeter of the outer sea-pen to deter California sea lions Zalophus californianus. Six 1-ton Danforth anchors were used to secure the net against the extreme tidal flux (up to $6.3 \mathrm{~m}$ ) and strong currents (up to 5.2 knots; $\sim 2.68 \mathrm{~m} \mathrm{~s}^{-1}$ ). A floating barge with solar-powered facilities for live fish housing, food fish preparation and cold storage, veterinary medical facilities, emergency equipment, and personnel support was anchored within the sea-pen.

\subsection{Search effort}

Search activities to locate vaquitas for capture included 3 primary components: (1) acoustic searching by means of a passive acoustic array established in and near the vaquita refuge; (2) visual searching by experienced observers; and (3) dolphin-assisted localization.

Decades-long experience with passive acoustic monitoring of vaquitas was critical to the success of daily search efforts. An array of 87 underwater autonomous passive acoustic odontocete detectors (C-PODs, www.chelonia.co.uk) was deployed from June to September 2017. This array expanded on the area monitored annually since 2011 to provide an acoustic assessment of trends in vaquita abundance (Jaramillo-Legorreta et al. 2017). The larger array was removed prior to the onset of October field efforts and a subset of 36 C-PODs was placed in the areas with the highest rates of vaquita acoustic detection, primarily in the western and southern portions of the vaquita refuge (see Fig. 1). It was later expanded with 8 additional C-PODs. Weather permitting, teams in small boats traveled to each sampling site on a daily basis, interchanged C-POD units, and brought them to shore for analysis. Areas where vaquitas were detected by the CPODS were reported to field team leaders between 02:00-03:00 $\mathrm{h}$ each day. The catch team and visual search team leaders considered these data, and sea conditions, as they made their plan each morning to guide the visual observers, who commenced their work at dawn. 
The visual search operation consisted of a liveaboard $39 \mathrm{~m}$ mother ship, the 'Maria Cleofas', and 2 smaller $(13 \mathrm{~m})$ search vessels. Three rigid-hulled inflatable boats (RHIBs) served as catch boats. US Navy dolphin tender boats assisted with localization (see end of this section), and Mexican Navy vessels assisted in aspects of sighting, catching, security, and transport. All vessels were equipped with automatic identification system (AIS) for real-time monitoring of their position by the leader of the search team aboard the 'Maria Cleofas'. The visual search team started each day's efforts at a site determined through passive acoustic detections from the previous day.

Vaquitas are small, and are typically found in small groups that surface inconspicuously and avoid vessels (Jaramillo-Legorreta et al. 1999). To maximize chances of finding animals to capture, all members of the visual search team had extensive prior survey experience with this species. The sighting platform on the 'Maria Cleofas' was $6.53 \mathrm{~m}$ above the water's surface and afforded a stable platform for 2 pairs of 'Bigeye' 25-power Fujinon binoculars. The 2 smaller vessels had flying bridges 2.69 and $2.46 \mathrm{~m}$, respectively, above the water and observers on these boats used handheld binoculars or binoculars on monopods. During search mode, the 3 primary search vessels moved in a shallow V-formation, separated by about $600 \mathrm{~m}$, with the 'Maria Cleofas' in the center and slightly behind the other 2 boats. A custom program was used to track each vessel using AIS data and plot the position of sighted vaquitas using compass angles and estimated distances. The search team was supplemented by the 3 RHIBs, which were deployed $300 \mathrm{~m}$ outside the primary search boats. The fleet moved together at about 9 knots $(4.63 \mathrm{~m}$ $\mathrm{s}^{-1}$ ). Once vaquitas were sighted, efforts were made to maneuver the 3 primary search boats into a triangle with the vaquitas in the center, to maintain visual contact, while directing the catch boats into position.

To supplement this visual search effort, US Navy bottlenose dolphins experienced in underwater swimmer detection (Renwick et al. 1997, Myers 2015) were employed to locate and track vaquitas at short ranges and to help guide the capture boats. In preparation for vaquita detection efforts, US Navy dolphins were deployed to San Francisco Bay where they searched for harbor porpoises utilizing their echolocation and detected them at a range of a few $100 \mathrm{~m}$. The dolphins were trained to search from below the bow of a small Navy vessel and provide a visual cue (e.g. a leap) when a porpoise was detected, to inform the capture team of the animal's location. When searching for vaquitas in the Gulf of California, the dolphin-tending vessel remained at a distance behind the visual search fleet, where it could bring the search dolphin to the sighting area within minutes following a very-high-frequency (VHF) radio message. Once the dolphin was called in to search, the tender moved to a location within a few $100 \mathrm{~m}$ of the most recent sighting and the dolphin was deployed.

\subsection{Catch and initial assessment}

The primary factors considered in selecting a safe and effective capture technique included: (1) the need for the animals to be able to surface to breathe once captured; (2) depth of the habitat (typically $>10$ m deep); (3) extreme turbidity of the Upper Gulf of California, which precludes seeing animals more than $1 \mathrm{~m}$ below the surface; (4) strong currents associated with extreme tides; and (5) the elusive nature of vaquitas. Several techniques were considered based on experience with closely related species, but ultimately gillnets used to capture harbor porpoises in Denmark and Greenland waters for telemetry research were adapted for vaquitas, although it was not known whether vaquitas would respond to boat chase techniques in the same manner as harbor porpoises (Nielsen et al. 2018, van Beest et al. 2018). Methods such as purse seines, weirs and herding into shallow waters were rejected due to concern over several factors, including the inability to observe vaquitas in turbid water, the possibility of net collapse, extreme tidal currents, and the elusive nature of vaquitas.

Modified monofilament gillnets, $260 \mathrm{~m}$ long and $9 \mathrm{~m}$ deep, with an $18 \mathrm{~cm}$ stretch mesh size, $0.7 \mathrm{~mm}$ twine diameter, no. 1.5 lead line and an iridescent green Hau-Danline-Deep Sea no. 7 floating line, were constructed in Denmark. The nets were designed to be deployed at fast speed over the stern of the RHIBs. The nets were marked by a flag at one end and a buoy on the other. Two $8 \mathrm{~m}$ fast RHIBs were used for net deployment and porpoise retrieval. Capture crews had expertise in porpoise catching, handling, and veterinary medicine. Once vaquitas were sighted from the RHIBs, one or more nets were set ahead of, and if possible around, the anticipated path of the animals. Each deployed net was monitored by one or more catch boats, while the other boat(s) attempted to herd vaquitas toward the nets. Once a vaquita was observed caught in the net, the closest boat moved in, disentangled the animal and 
lifted it onto a stretcher. The stretcher containing the vaquita was either held beside the capture boat, or placed inside a soft-sided transport container padded with and placed on foam that contained enough water to relieve pressure on the animal's thorax. Once it appeared stable, the vaquita was transported to one of the housing facilities. If the animal appeared agitated, the boat was slowed until the animal appeared calmer. Drugs and equipment for sedation, emergency resuscitation and supportive care were available on each transport boat. Satellitelinked SPOT fin-mount tags (Wildlife Computers), attached by a single delrin pin to the dorsal fin, were available so that a vaquita could be tagged within minutes if emergency release for animal safety was deemed necessary.

\subsection{Veterinary assessment}

The VaquitaCPR team included more than 15 veterinarians and veterinary technicians with experience in all aspects of cetacean medicine. Detailed protocols were developed prior to the field effort for all aspects of handling and care. Once a vaquita was captured, a clinical assessment was made, noting respiratory rate (RR) and character (deep or shallow), heart rate (HR) and rhythm (using stethoscope, hand contact or portable ECG unit), and behavior. Sex, length, and any external injuries were recorded, and an assessment was made of age class (juvenile or adult). A SonoSite Edge portable ultrasound system (FujiFilm), with a C60x 5-2 MHz curvilinear transducer and outfitted with Zeiss Cinemizer heads-up display goggles, was used for thoracic and abdominal examination, including pregnancy determination. During transport, RR was monitored continuously, HR intermittently, and blood was collected from the periarterial venous rete of the fluke using a 23G butterfly catheter into EDTA, serum separator, and heparinized BD Vacutainer ${ }^{\circledR}$ tubes. Hematology and serum chemistry parameters were analyzed at the SeaWorld Clinical Pathology Laboratory in San Diego, serum cortisol levels were measured at Cornell University, plasma catecholamines at Mystic Aquarium, and creatinine kinase isoenzymes at the University of Miami Avian and Wildlife Laboratory. Additionally, blood was collected into a PICO syringe for rapid chemistry analysis using an iSTAT point-ofcare handheld blood analyzer with CHEM8+ cartridge. Once animals were transferred to either softsided pools or sea-pens, respiration and behavior were monitored continuously.

\subsection{Age determination}

Teeth collected post mortem were decalcified and thin-sectioned following standard protocols (Perrin \& Myrick 1980). After staining with hematoxylin, age was estimated by counting growth-layer groups (GLGs), which are annual patterns of dark and light lines in the dentine and cementum. Age was estimated independently by 3 experts and a final age was derived by consensus.

\section{RESULTS}

Search and capture efforts were conducted on 11 full or partial field days from 13 October to 4 November 2017. Vaquitas were sighted on 8 d, they were kept in view consistently enough for the nets to be deployed on $3 \mathrm{~d}$ at 3 different sites, and vaquitas were caught on $2 \mathrm{~d}$. The first vaquita, caught on 18 October, was a juvenile female (V01F) which was released within hours of capture due to symptoms of stress. The second, caught on 4 November, was an adult female (V02F), which died on the day of capture.

\subsection{Search efforts}

Acoustic data were available from 964 site-days. Vaquita vocal activity was found at 21 of the 36 sites in the original network and at 23 sites of the expanded network (see Fig. 1). The acoustic activity was intense at 2 of the sites, at which there was persistent vocal activity. In total, 125 vaquita acoustic encounters were detected. This near real-time acoustic information was critical in guiding the visual search team toward areas with recent vaquita detections.

As in past studies (Silber 1988, Taylor et al. 2017), the most common group size observed was 2 , and there was some difficulty in distinguishing mother/ calf pairs from pairs of older animals. Calves were approximately 6 mo old during the field season, as most births occur from February to April (Hohn et al. 1996). Many animals responded to the approach of the catch vessels by forming tight pairs and porpoising to avoid the pursuit boats. In such cases, size differences between adults and juveniles were more obvious, although still challenging to discern.

Navy dolphins were utilized for initial detection of vaquitas only on the first day, as the use of multiple vessels to locate and track vaquitas visually proved 
more successful than anticipated. However, in several instances, vaquitas eluded visual contact after surfacing in the middle of the vessel formation and in very calm waters. Navy dolphins were deployed twice to try and locate lost sightings but without success. Once, Navy dolphins relocated the vaquitas at the same time as vaquitas were visually relocated. Operational conditions complicated the dolphins' ability to perform this task, as the dolphins were trained to search from below the bow of a small boat. This boat may have deterred vaquitas, as they maintained a distance of several $100 \mathrm{~m}$ from any motorized vessels. Furthermore, the dolphins were trained to use echolocation to locate porpoises, which is likely effective only at distances of a few $100 \mathrm{~m}$. Despite these obstacles, Navy dolphins did relocate a vaquita on 1 occasion when observers had lost track of the animal.

It was possible to herd vaquitas for about $1 \mathrm{~km}$ towards the nets by operating the catch RHIBs at high speed near the animals. In the first event, a young female was captured (V01F, see Section 3.2.). Two other individuals in the group were then pursued for about $2 \mathrm{~h}$, but it was difficult to determine if the same individuals were pursued during the whole period. During the pursuit the animals were observed to swim around and under the net, confirming that vaquitas can detect and avoid nets in some situations (i.e. set on the surface during daylight). Following capture of the second animal (VO2F), 1 or 2 other individuals in the vicinity (one of which may have been entangled with VO2F but escaped) were successfully herded back towards the nets, but ultimately eluded capture. Pursuit of vaquitas in the vicinity of the V02F capture lasted for 90 min until dusk.

\subsection{Captures}

\subsubsection{V01F}

The first vaquita (V01F), a juvenile female, $102 \mathrm{~cm}$ long, weighing $\sim 20 \mathrm{~kg}$, was caught in a net set near a group of 3 animals at 10:56 h on 18 October 2017 (see Table S1 in the Supplement at www.int-res.com/ articles/suppl/n038p011_supp.pdf for a timeline of events). In spite of its small size, it was able to easily lift the net to the surface and breathe until it was disentangled and lifted out of the net (Fig. 2). The vaquita was placed in the stretcher, suspended in a seawater-filled transport container, and transported to the shore-based pool. Initial HR was $~ 150$ beats $\min ^{-1}(\mathrm{bpm})$ with no sinus arrhythmia (defined as higher HR immediately after a respiration and lower

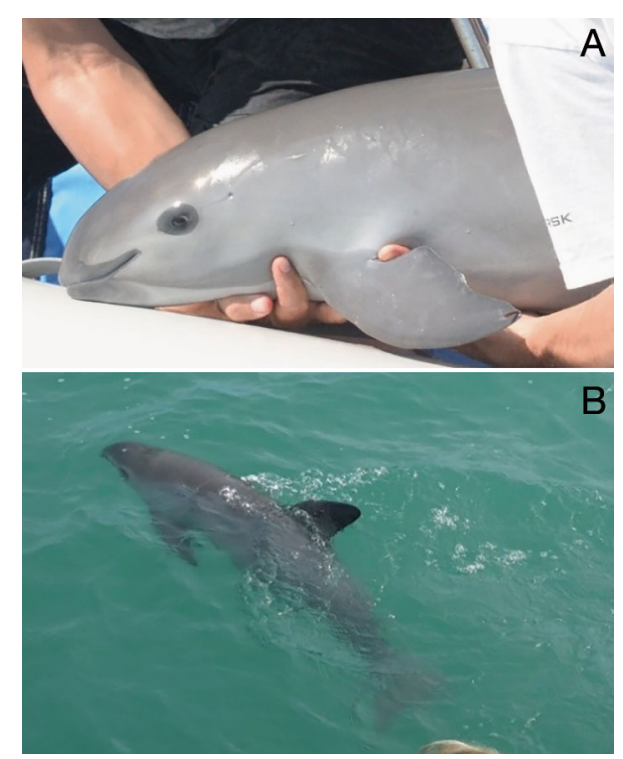

Fig. 2. Vaquita $\operatorname{V01F}(\mathrm{A})$ at capture and (B) at release

HR immediately prior to a respiration; characteristic of cetacean breathing) and $\mathrm{RR}>10 \mathrm{~min}^{-1}$. Diazepam was administered as deemed appropriate to mitigate stress (Table S1). During transport, HR lowered slightly to $\sim 130 \mathrm{bpm}$ and $\mathrm{RR}$ reduced to $\sim 8 \mathrm{~min}^{-1}$.

Once released into the pool, the vaquita swam erratically, mostly along the pool perimeter, and repeatedly collided with the pool sides and personnel deployed in the pool to deflect it from the sides. HR averaged $\sim 150 \mathrm{bpm}$ with no detectable sinus arrhythmia (intermittently measured when animal was handled to divert from the pool sides) and RR increased to $\sim 10 \mathrm{~min}^{-1}$ (continuously monitored). After approximately $1 \mathrm{~h}$ in the pool, white foam was observed emanating from the blow-hole, suggesting the development of pulmonary edema. Furosemide at $4 \mathrm{mg} \mathrm{kg}^{-1}$ intramuscularly (IM) and methylprednisolone sodium succinate $5 \mathrm{mg} \mathrm{kg}^{-1} \mathrm{IM}$ were administered, and the foam disappeared within $5 \mathrm{~min}$ and was not observed again. At this point, due to the continuation of agitated behavior, the decision was made to move the vaquita to the sea-pen, because its sloping sides would present less of a collision risk. In the sea-pen, V01F continued to appear agitated, and its behavior deteriorated slightly, with increased lifting of the head out of the water, and erratic swimming patterns. The decision was then made to release the animal as close as possible to its capture site, where other vaquitas had been observed. The animal was transported back to the refuge in the same stretcher and container as described above. During transport, HR was 130-160 bpm and RR stabilized at $~ 8 \mathrm{~min}^{-1}$. 
Blood was collected during transport for serum chemistry, hematology and serum cortisol assessments (see Table S3). Blood results demonstrated a typical cetacean stress response (Atkinson \& Dierauf 2018), characterized by elevated cortisol (23.4 $\mu \mathrm{g}$ $\mathrm{dl}^{-1}$ ) and a neutrophilia (92\% of the total white blood cell count) with lymphopenia (5\% of the total white blood cell count). Based on the blood cortisol level, which was about 10-fold higher than values reported in a variety of live-handled odontocetes (Atkinson \& Dierauf 2018), V01F developed a profound stress response to handling, consistent with its outward clinical signs. Blood results also showed elevated creatine kinase (CK) (4244 $\mathrm{U} \mathrm{l}^{-1}$ ), elevated lactate dehydrogenase (LDH) (1919 $\mathrm{U} \mathrm{l}^{-1}$ ) and hypoglobulinemia $\left(1.3 \mathrm{~g} \mathrm{dl}^{-1}\right)$, compared to published values for harbor porpoises released from herring Clupea harengus weirs (Koopman et al. 1995, 1999), captive finless porpoises (Kasamatsu et al. 2012), and Stenella chased and encircled in the Eastern Tropical Pacific (St. Aubin et al. 2013). Elevation of blood CK and LDH levels indicate leakage of these enzymes from damaged skeletal muscle cells, suggesting that some myopathy occurred.

During transport to the release site, while respiration rate had stabilized, morphometric measurements were recorded, and an $8 \mathrm{~mm}$ diameter skin and blubber punch biopsy to be used for cell culture and cryopreservation was collected from the right dorsum at the level of the caudal margin of the dorsal fin, following an anesthetic ring block using lidocaine with epinephrine. The biopsy was placed in transport media with antibiotics and fungicide and refrigerated overnight (see Houck et al. 2017). The following day, the sample was shaken to dislodge external debris, decanted into a second transport vial, and transported to NOAA Southwest Fisheries Science Center, La Jolla, USA, where blubber was separated, dabbed on the culture plate to remove transport media and frozen at $-80^{\circ} \mathrm{C}$. The remaining skin was sectioned, one third was archived at $-80^{\circ} \mathrm{C}$, the remaining 2-thirds were placed into fresh transport media and transported on wet ice to San Diego Zoo Global's Frozen Zoo for cell culture and cryopreservation (see Houck et al. 2017). These live cells from vaquitas can be used in eventual future deextinction programs.

Upon return to the sea, VO1F continued to swim at the surface, lifting its head regularly out of the water, and then began to make short dives over the next 20 min until visual contact was lost. The fate of V01 is unknown; no carcass was discovered despite considerable human presence in the area over the weeks following capture, and the fin was not identified in photographic identification records from efforts continued through 10 November 2017. The animal was not tagged due to its small size and concern for potential impacts of such tags on its health.

\subsubsection{V02F}

On 4 November 2017 at 16:18 h, 2 vaquitas were caught in a net deployed approximately 15 min earlier. Both were visible at the surface, and the catch boats immediately approached the net. One vaquita was loosely entangled and escaped; the other was entangled with net around the head and flippers, but was able to lift the net to the surface to breathe. While attempts were made to recapture the second animal, V02F was monitored while being held in a stretcher in the water alongside the boat. This animal was an adult female $(40 \mathrm{~kg}$ and $136 \mathrm{~cm}$ standard length), in good body condition, and was calm and alert during initial handling (Table S2). The animal appeared stable with a HR that consistently ranged from 120-130 bpm, with no detectable sinus arrhythmia, and $\mathrm{RR}$ of $\sim 6 \mathrm{~min}^{-1}$. In an attempt to mitigate stress and assist with acclimation, the animal received diazepam at $0.175 \mathrm{mg} \mathrm{kg}^{-1} \mathrm{IM}$.

Diagnostic ultrasound of the animal's thorax performed over the side of the boat while the animal was in the water was initially normal, but 50 min postcapture showed evidence of alveolar interstitial syndrome developing in the ventral portion of both lungs (see Fig. 3). This finding was considered consistent with developing pulmonary edema based on ultrasound appearance, distribution of affected lungs, and rapid onset (Smith et al. 2012). The animal received furosemide (1 $\mathrm{mg} \mathrm{kg}^{-1}$ ) and methylprednisolone sodium succinate $\left(5 \mathrm{mg} \mathrm{kg}{ }^{-1}\right)$ IM. A recheck ultrasound after drug therapy showed significant improvement on the left side but only partial improvement on the right (Fig. 3). A second dose of furosemide was administered which resulted in complete resolution of the abnormal pulmonary finding when rechecked 13 min later (see Table S2 for a timeline).

Once efforts to catch the other vaquita were discontinued, V02F was suspended in a stretcher inside a transport container and taken to the sea-pen. During transport, the animal's HR was stable at $\sim 120 \mathrm{~min}^{-1}$ and $\mathrm{RR}$ rarely varied from $\sim 6-8 \mathrm{~min}^{-1}$. Upon introduction to the sea-pen, the animal appeared agitated and avoided the net pen walls, maneuvering to avoid collisions. Despite behavioral indications that the animal 


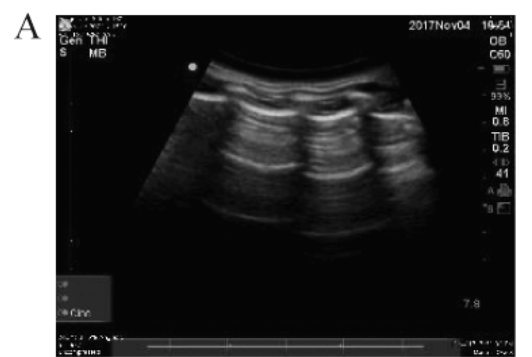

Left lung: No abnormalities

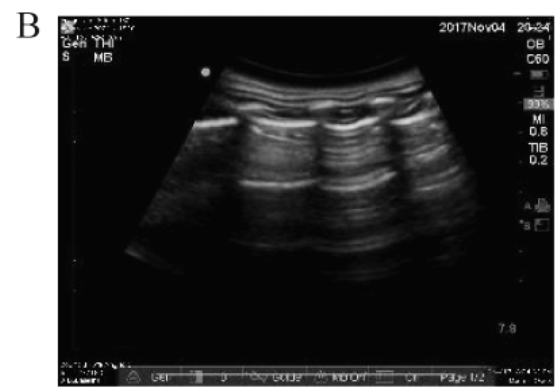

Left lung: No abnormalities

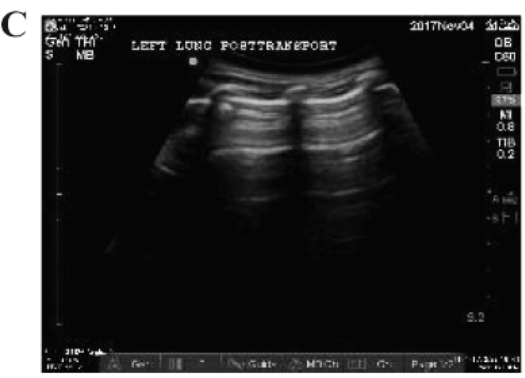

Left lung: No abnormalities

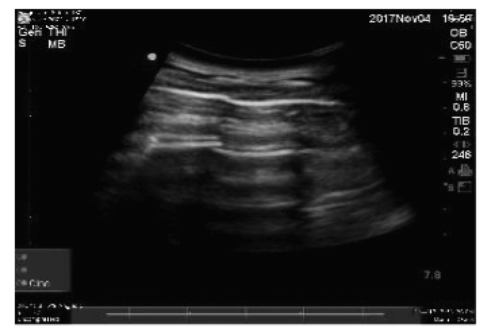

Right lung: No abnormalities

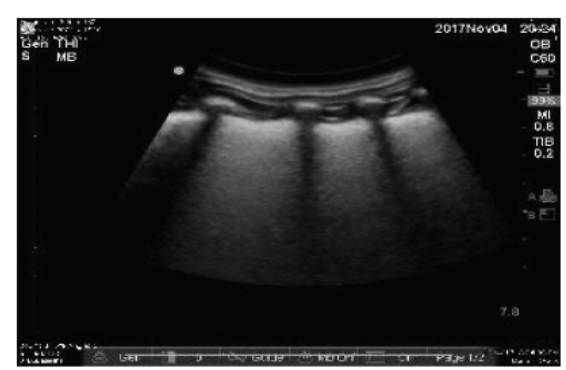

Right lung: Severe AIS in ventral portion

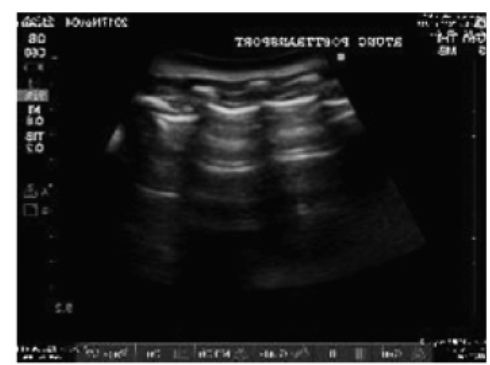

Right lung: No abnormalities

Fig. 3. Ultrasound images of vaquita V02F lung fields. (A) Initial scan, lungs appear normal; (B) ultrasound scan after the first dose of furosemide, with resolution of edema in the left lung but persistence of alveolar interstitial syndrome (AIS) in the ventral right lung; $(\mathrm{C})$ ultrasound scan after treatment showing resolution of AIS, no abnormalities in either lung

was beginning to acclimatize, the animal abruptly deteriorated, characterized by decreased awareness of surroundings and prolonged respiratory interval. V02F was released approximately $4 \mathrm{~h}$ after capture, but suffered a cardiac arrest upon release.

Emergency resuscitation efforts were initiated (see Table S2), which included intubation (7.5 mm endotracheal tube), ventilation, oxygen administration, chest compressions as needed, emergency medications, intravenous and subcutaneous fluid administration, preparation of the dorsal fin for potential tagging if release became an option, and continuous monitoring. The veterinary team was able to restart the vaquita's heart, but they were gravely concerned about inadequate peripheral vascular perfusion and inability to transition from occasional spontaneous but ineffective respirations to effective spontaneous ventilation. Finally, the team was unable to reverse a cardiac arrest and V02F died $3 \mathrm{~h}$ after attempted release.
A post mortem examination was conducted within $1 \mathrm{~h}$ of death, and representative samples of all major organs were fixed in 10\% neutral buffered formalin for histological examination. The reproductive tract was examined, then placed in a plastic bag moistened with sterile saline for further evaluation and gamete archiving at SeaWorld laboratory. Samples for cell culture were collected using sterile forceps from kidney, trachea, liver and mesovarium, placed into cell culture transport media, and transported to San Diego Zoo within $48 \mathrm{~h}$ of collection for processing for cell culture and cryopreservation as described in Houck et al. 2017.

On gross examination, all internal organs appeared within normal limits, and the teeth were worn, suggesting old age. There was no evidence of current pregnancy or lactation, although the ovaries had corpora indicative of previous ovulations, with a corpus luteum on the left ovary which was confirmed 
to be functional by a concurrent serum progesterone concentration that was above baseline $\left(5 \mathrm{ng} \mathrm{ml}^{-1}\right)$ (see Table S3). Multiple linear scars and fluke/fin notches typical of healed previous entanglement injuries were present. The fore-stomach contained semi-digested fish.

GLG patterns in the teeth were poorly defined and there was considerable variation in the number of accessory lines present within each annual GLG. Despite these challenges, a final age estimate of $15 \mathrm{yr}$ was determined. This estimate was validated by cementum layer counts by one of the people counting GLGs. It is worth noting that because of the difficulties in counting GLGs near the pulp cavity, V02F could have been older than its estimated age.

Histological examination revealed myocardial and skeletal muscle degeneration and necrosis with concurrent loss of myoglobin staining in necrotic myocytes noted on immunohistochemical staining of tissue with an anti-myoglobin antibody (MyoG, AR012, BioGenex) (Fig. 4). Renal tubular degeneration and necrosis were noted with accumulation of myoglobin within tubule lumens consistent with myoglobinuric nephrosis. These findings indicate that the death of V02F was due to capture myopathy. There was no evidence of any underlying chronic disease that could have contributed to death. Additional histologic findings were subclinical and primarily associated with older age and parasitic infection (Table 1).

Blood collected at the end of transport and during emergency response showed no significant hematological changes, except hyperglycemia, with elevated creatinine kinase and lactate dehydrogenase levels compared to other porpoises (as above for V01F) (Table S3). Creatinine kinase elevations consisted predominantly of the $\mathrm{mm}$ (skeletal muscle derived) and mb (cardiac muscle and diaphragm derived) isoenzymes, rather than the bb (brain derived) isoenzyme. These data indicate that most CK enzyme was from skeletal muscle rather than brain, supporting a diagnosis of skeletal myopathy. Hormonal analyses of blood collected at 20:00 h, which was 26 min after the first cardiac arrest during emergency resuscitation, revealed high cortisol, aldosterone, epinephrine and norepinephrine levels, indicative of a severe acute stress response (Table S3). Cortisol levels were 100-fold higher than levels reported in a variety of handled odontocetes, and epinephrine and norepinephrine were at the highest levels reported to date for cetaceans (Atkinson \& Dierauf 2018). However, as the sample was collected during emergency resus- citation, caution must be taken when interpreting these values.

Following the death of V02F, further capture efforts were suspended immediately. The behavior of the first animal, respiratory rates and blood cortisol levels typical of acute stress, the development of pulmonary edema in both animals, and the death of the adult female suggested that both capture and containment posed excessive stress for vaquitas. It is unknown whether or not the responses of these individuals should be expected for all vaquitas, and whether the use of sedative or vasoactive drugs could ameliorate the stress. But, with fewer than 30 vaquitas remaining, the field team decided, and the IRP concurred, that captures be suspended because the risk of mortality to the remaining individuals was deemed high.

\subsection{Photo-identification}

Upon cessation of capture efforts, field assets were redirected toward photographic identification for the remainder of the field season. Acoustic searching continued until 8 November at all 44 sites and until 9 November at the 3 sites with the highest acoustic encounter rates. During capture efforts, photographs indicated sufficient markings to identify some individuals, such that the potential to obtain an independent estimate of abundance using photo-identification warranted further exploration. Distinctive dorsal fin notches and shapes have been used previously to identify individual vaquitas (Jefferson et al. 2009). In an attempt to refine abundance estimates and learn about vaquita ranging patterns, dedicated photographic identification efforts were made on all workable field days after cessation of capture attempts on 4 November. Experienced photographers with telephoto lenses of at least $300 \mathrm{~mm}$ were distributed across 3 catch boats and the smaller search vessels in an attempt to obtain high-quality, high-resolution dorsal fin images. Upon initial sighting by observers on the primary search vessel 'Maria Cleofas', the closest smaller vessels attempted to approach for photographs. Poor weather and elusiveness of the porpoises limited the number of photographs collected during these efforts, with dedicated photo-identification operations possible on only $3 \mathrm{~d}$. Over the duration of the entire project, 192 images from 7 photographers were examined. Seven individual vaquitas were documented, including the 2 captured porpoises. Three fins were very similar to those documented by Jefferson et al. (2009), but 


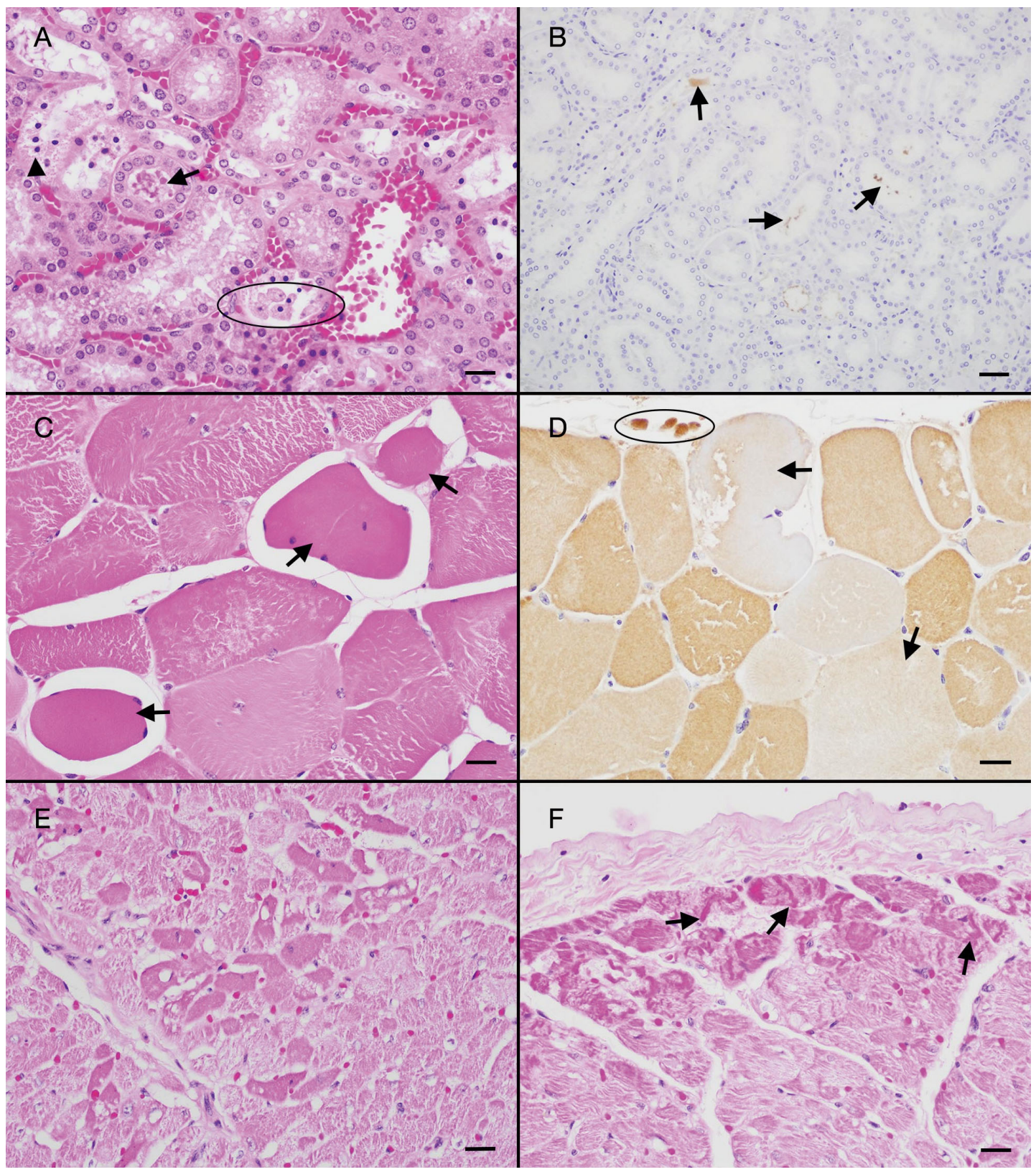

Fig. 4. Tissues from vaquita V02 stained with hematoxylin and eosin (A,C,E,F) and an anti-myoglobin antibody (B,D). (A,B) Kidney with myoglobinuric nephrosis. Renal tubules contain myoglobin (arrows) and sloughed necrotic cells (ellipse). Scattered tubular epithelial cells are necrotic (arrowhead). (C,D) Shrunken necrotic skeletal myocytes with loss of cross striations and myoglobin staining (arrows). Accumulations of myoglobin adjacent to affected myocytes (ellipse). (E,F) Sections of heart with myofiber degeneration and contraction band necrosis (arrows). Scale bars $=20 \mu \mathrm{m}$

photo quality was insufficient to confirm matches. The nature of some of the fin markings is suggestive of previous interactions with fishing gear, indicating that at least some individuals may have been able to survive some entanglements and perhaps explaining how some observed vaquitas appeared to be familiar with nets and their avoidance.

\section{DISCUSSION}

\subsection{Vaquitas}

The protocols developed to detect vaquitas using acoustic and visual methods resulted in finding vaquitas on all 6 full good-weather days. The strat- 
Table 1. Histologic findings in V02F. No lesions were observed in the eyes or gastrointestinal tract

\begin{tabular}{|c|c|c|}
\hline Tissue & Lesion & Most likely cause \\
\hline Brain & Marked neuronal lipofuscin accumulation & Age related \\
\hline Heart & $\begin{array}{l}\text { Marked acute myocardial degeneration, } \\
\text { contraction band necrosis, myocardial edema }\end{array}$ & $\begin{array}{l}\text { Capture-related stress and catecholamine } \\
\text { release; acidosis }\end{array}$ \\
\hline Blood vessels & Mild arteriosclerosis & Age related \\
\hline Lung & $\begin{array}{l}\text { Acute neutrophilic bronchitis and bronchiolitis } \\
\text { with foreign material } \\
\text { Peribronchiolar concretions } \\
\text { Mild focal histiocytic pneumonia }\end{array}$ & $\begin{array}{l}\text { Gastric material aspiration during capture or } \\
\text { emergency medical procedures } \\
\text { Previous lungworm infection } \\
\text { Previous lungworm infection }\end{array}$ \\
\hline Liver & $\begin{array}{l}\text { Focal biliary cyst } \\
\text { Hepatocyte hemosiderin accumulation }\end{array}$ & $\begin{array}{l}\text { Trematode infection } \\
\text { Unknown }\end{array}$ \\
\hline Marginal lymph node & Moderate anthracosis & Inhalation of dust particles \\
\hline Spleen & $\begin{array}{l}\text { Mild lymphoid hyperplasia } \\
\text { Mild hemosiderosis }\end{array}$ & $\begin{array}{l}\text { Antigenic stimulation } \\
\text { Unknown }\end{array}$ \\
\hline Kidneys & $\begin{array}{l}\text { Moderate acute tubular degeneration and } \\
\text { necrosis with luminal myoglobin }\end{array}$ & $\begin{array}{l}\text { Release of myoglobin from damaged } \\
\text { myocytes (myoglobinuric nephrosis) }\end{array}$ \\
\hline $\begin{array}{l}\text { Skeletal muscle } \\
\text { (neck and head) }\end{array}$ & Moderate acute degeneration and necrosis & $\begin{array}{l}\text { Capture-related stress and catecholamine } \\
\text { release }\end{array}$ \\
\hline Skin & Acute laceration & Net entanglement prior to capture \\
\hline Uterus & $\begin{array}{l}\text { Endometrial polyp } \\
\text { Vascular hyalinization }\end{array}$ & $\begin{array}{l}\text { Age related } \\
\text { Previous pregnancy }\end{array}$ \\
\hline
\end{tabular}

egy of using multiple observation vessels with a large ship capable of tracking sightings from all vessels facilitated the location and tracking of groups in real time. Capture of the 2 vaquitas occurred rapidly after net deployment (on 2 out of 3 net deployments), although attempts to catch other vaquitas in the vicinity were unsuccessful, as these vaquitas appeared to detect and evade the nets. All remaining vaquitas have survived intense gillnet fishing efforts and some, including V02F, had scars consistent with having been previously entangled. However, the death of 4 individuals in spring 2017 and an adult female in spring 2018 (after this ex situ effort) with clear entanglement lesions, indicate that despite their evasive behaviors, death from entanglement continues. All of the vaquitas observed during field operations, including the 2 captured individuals, appeared in excellent body condition.

\subsection{Capture and holding}

The light capture nets posed minimal physical threat to the vaquitas during capture. However, both captured vaquitas showed behavior, clinical signs and blood parameter changes typical of a marked stress response. The blood cortisol levels in V01F during transport were 10 -fold lower than those in V02F during resuscitation, but 10 -fold higher than levels in bottlenose dolphins that have been caught and released for health assessments (Hart et al. 2015). Thus, this animal was undergoing an adrenal stress response, but apparently a less severe one than V02F. To the best of our knowledge, there are no published comparative data on catecholamine (adrenal norepinephrine and epinephrine hormones) levels in cetaceans that died of capture myopathy. The very high cortisol and catecholamine levels, coupled with the high muscle enzyme values indicative of muscle breakdown, support a diagnosis of stressinduced capture myopathy in V02F. The post mortem lesions in this animal were highly consistent with lesions previously reported in cetaceans and other species, including humans, associated with stress and catecholamine release or exposure (Jiang \& Downing 1990, Cowan \& Curry 2008, Herráez et al. 2013). The respiratory acidosis that developed following initial cardiac arrest may have also contributed to myocardial degeneration and necrosis. What remains unclear is when the severe stress 
response was initiated. V02F appeared calm following capture, and the external signs of stress were most apparent when swimming in the net pen, but the early onset of pulmonary edema in both animals, which is an uncommon finding in otherwise healthy cetaceans, suggests chase and capture likely triggered an initial stress response. Edema may be secondary to catecholamine surge and has been shown to develop rapidly (several hours) in humans secondary to emotional stress cardiomyopathy (Pavin et al. 1997). Additionally, muscle, heart, and renal lesions in V02F were well developed at the time of death, further suggesting early onset of stress during chase, capture and handling. Though mild acute aspiration pneumonia was noted, this lesion was not deemed severe enough to have contributed to respiratory or cardiac arrest. V02F was an older animal with some organ changes characteristic of aging in other cetaceans (see Table 1). Whether old age enhanced the effects of capture and handling on stress is unknown. Furthermore, the small size of the vaquita population could have resulted in few individual animals being chased repeatedly on subsequent days before capture, thus potentially stressing animals prior to the day of the actual capture and handling

To understand the stages of stress development in these animals, a precautionary step-wise approach to assess the responses to each stage (pursuit, capture, handling, transport, enclosure) separately would have been ideal. This was in the initial plan developed in 2015 (see Annex 3, CIRVA-7 2016), but was not implemented due to the dire conservation status of the species when field efforts were initiated. Instead, in 2017 the aim was to catch as many vaquitas as possible of any age and sex, and place all animals caught into enclosures, with release as an emergency option if animals did not adapt to the enclosure. Research on the stages of this stress response should be conducted on animals from healthy populations of small cetaceans that are not facing imminent extinction. Furthermore, as there are no data on the response of vaquitas to medications, a precautionary approach using drugs that have been widely used on a range of marine mammal species with no side effects was adopted (Gulland et al. 2018). Given the observations on these 2 vaquitas, research on clinical treatment of stranded cetaceans should include evaluation of the effects of stronger sedatives and therapeutics effective in managing cardiovascular effects of catecholamines, such as beta-blockers.

To reduce risks of cardiomyopathy and capture myopathy in any future operations, consideration should be given to translocation rather than confinement. If confinement is used in early stages, even temporary pools should be designed to minimize stress on individual animals. The holding pools used in this field effort were intended for short-term use until funds for construction of a sanctuary lagoon were available. These funds were contingent upon demonstration that capture of vaquitas was possible. It is possible that immediate use of a larger enclosure might have reduced stress.

\subsection{Planning and logistics}

The idea of an ex situ approach to vaquita conservation, 'which would involve removing individuals from the wild population, either to develop a captive breeding program or to safeguard the last few individuals of the species' was considered and rejected by CIRVA in 2014 (CIRVA-5 2014, p. 19). This decision was based on a number of reasons, including the difficulty of finding and capturing live animals, the risk to the survival of the animals during the capture process, the low survival rate and breeding success in captivity of small cetacean species not previously held in captivity, the absence of suitable facilities in Baja to house vaquitas, and the difficulties of permitting and transport to US facilities (CIRVA-5 2014). In addition, although not specified in the CIRVA-5 (2014) report, the recovery team was concerned that efforts to eliminate gillnets from the vaquita habitat would be hampered by such an approach. As the situation in the wild worsened, exploration of possible ex situ conservation options was initiated in early 2015 through an independent process that explored whether an ex situ option might be feasible, and developed a staged, precautionary plan.

The initiation of ex situ efforts in 2017 resulted in acceleration of the originally planned phased, precautionary approach, and did not allow for construction of a large sanctuary before animals were caught. Had the program started earlier, when the vaquita population was larger (several 100s of animals rather than 10s), there would have been more time to execute a step-wise approach that could have evaluated the vaquitas' responses to capture, enclosure, diet and social grouping, as well as to release after temporary capture. If more animals had been available in the wild, initial capture and handling procedures could have been developed on juvenile male animals rather than reproductive females, reducing population level impacts from accidental loss of an individual. In the early stages of the California condor 
Gymnogyps californianus capture and reintroduction project, a chick died after handling, but protocols were adapted and the program ultimately saved the species from extinction (Goodall et al. 2009). A larger population from which to select target animals could also reduce the number of times a specific individual was pursued for capture, so reducing stress on the individual. Thus, future efforts that propose use of ex situ actions for other small cetaceans should be initiated while populations are large enough to afford the potential loss of individual animals, and to allow for selection of juvenile male animals for technique development. If time is available for a staged approach to be taken, each step can be evaluated before progressing to the next one. This would allow use of an adaptive management approach, with progression based on evaluation of the results from each stage. Specifically, responses to chase, capture, handling and enclosure should be evaluated separately, and methods to mitigate adverse responses, particularly stress, evaluated. Sedatives and therapeutic drugs to counteract effects of cortisol and catecholamines could be evaluated (see Gulland et al. 2018). These methods could be developed for taxonomically similar small cetaceans that are not facing imminent extinction. The results of such advanced studies could have provided more explicit guidance on maximum durations of chase and handling times, as well as an evaluation of potential responses to captivity in enclosures of varying sizes. Despite the rapid time line from decision to capture vaquitas to field efforts, a large, international, multidisciplinary team was assembled, with shared leadership and expertise across institutions and individuals that was essential to keeping the project on track. Strong support from the Mexican and US Governments was essential for all aspects of the project, from fund-raising and donor comfort, to security, facility construction and on-thewater operations.

\subsection{Political and public opinion}

As predicted, the notion of an ex situ approach when first presented at CIRVA-7 was embraced by Mexican authorities as a promising avenue in an extremely dire situation. CIRVA, which responded cautiously to the initial presentation, emphasized that priority must remain on protecting the wild population even while exploring captive approaches. The GoM followed the recommendations not only to support VaquitaCPR, but also to increase netremoval efforts and enhance enforcement. Initiating
VaquitaCPR planning did not detract from establishment of a gillnet ban, rather it emphasized the need: gillnets (except those set for curvina and sierra) were banned on 30 June 2017: www.dof. gob.mx/nota_detalle.php? codigo $=5488674 \&$ fecha $=30 / 06 / 2017$ (in Spanish). VaquitaCPR cost approximately US\$ 5 million. In contrast, over US\$ 64 million have been spent in the last $2.5 \mathrm{yr}$ (20162018) in efforts to develop non-gillnet gear and financial compensation schemes for fishermen in the Upper Gulf of California (www.gob.mx/conanp/ acciones-y-programas/programa-de-conservacionde-especies-en-riesgo-procer; in Spanish), indicating that concurrent effort to find in situ remedies was considerable.

Despite many past efforts to communicate the plight of vaquitas to the world, the VaquitaCPR effort received the most intense media coverage and public attention to date. One strong thread of the story involved the potential of one group of marine mammals, the Navy dolphins, to save another, vaquitas. The compressed timeline forced by the rapid slide towards extinction and the focus on logistics to assemble and deploy the large capture team limited leverage of this international and national attention in a positive way within the local communities of San Felipe and El Golfo de Santa Clara. The VaquitaCPR team did not include dedicated community outreach because the funds available were barely enough to meet basic project expenses and the assembled experts lacked the skills to mount such an effort in México.

VaquitaCPR was not intended as a substitute for the broader socio-economic solutions needed to conserve the marine wildlife of the Upper Gulf of California. It was an emergency measure initiated in the face of the extreme decline of the vaquita despite a suite of legislative, enforcement, and development actions intended to stem this decline. The goal of salvaging some individuals and protecting them until their habitat was gillnet-free was ambitious and attempted only to buy time as an alternative to extinction. The field effort was complex, and there was no previous experience, or luxury of time, to guide refinements of the methods.

Ultimately, the political attractiveness of VaquitaCPR appears to have contributed to enhanced in situ measures and greater media focus on the plight of the vaquita, but the species continues to teeter at the very brink of extinction (Crosta \& Sutherland 2017). Global awareness of the plight of the vaquita has been bolstered, and continues to drive the cycle of efforts invested in net retrieval within the vaquita 
refuge. In the end, the efforts of VaquitaCPR did not compromise funding or the implementation of other conservation actions.

VaquitaCPR followed the failure of efforts over the past few decades to find alternatives to the use of gillnets in the Upper Gulf. Those efforts to find legal solutions were complicated, slow and difficult, with conflicts arising between the fishing communities and those seeking to conserve vaquitas. The sudden, unexpected emergence of the illegal totoaba fishery sidelined any normal societal efforts to meet the goals of vaquita conservation, biodiversity protection, and socio-economic viability in the upper Gulf of California. The rapid decline of the vaquita stands as an important lesson on the vulnerability of critically endangered species to sudden changes in threats and highlights the need for longer-term contingency planning well before a species reaches such critical levels of conservation concern.

Acknowledgements. Manuscript authorship represents the management team for this project. We thank the entire VaquitaCPR field team and all those who worked alongside us in San Felipe (G. Alker, J. Allen, S. Amozurrutia, J. Antrim, D. Bader, L. Ballance, A. Barleycorn, J. Barlow, A. Blancaforte, A. Borilla, D. Breese, S. M. Burton, S. Calderan, V. Cendejas, K. Coughlin, R. Daniels, J. Danoff-Berg, M. Dire, K. Danil, J. Dunham, B. Duryee, W. Elsen, J. C. H. Fernandez, J. Filamor, L. Fish, K. Forney, E. Franks, J. Gilpatrick, M. Gizowski, AC Ü, S. Hanson, K. Harding, A. Henry, S. Higgins, R. Holland, K. Kreuger, T. Jefferson, C. Lamendola, C. LeBert, K. Loflin, B. Lopez, J. Malloy, R. Martinson, J. McDaniel, J. Meegan, S. Mesnick, W. Musser, M. Nájera, J.V. Ocampo, C. Oedekoven, H. Ohara-Quesada, R. Olds, R. Pitman, M. Ponce Amaya, T. Pusser, V. Resendez, H. Rico, I. Rodriguez, J. Rodriguez, P. Rodriguez, M. Rohr, J.C. Salinas, B. Sarmiento, M. Schaaf, D. Schreher, A. Smith, J. Smith, S. Stevenson, E. Vasquez, I. Vomend, B. Weisman, S. Yin, N. Young, GSD; H. Nollens, C. Parry, R. Rivera, and T. Romano for blood sample analyses; T. Robeck and N. Stedman for examination of ovarian tissue; O. Ryder and M. Houck for tissue archiving; and A. Hall, J. Urban, N. Gales, J. McBain, and R. R. Reeves for serving on the IRP. Six fishermen were highly efficient managing deployments of acoustic detectors. We thank CIRVA for their advice and guidance throughout this effort. All animal handling was conducted under permit no. SGPA/DGVS/07534/17. Vaquita sample collection, shipping and international transport was conducted under MMPA permits nos. 18786-02 and 19091; and CITES permits MX90273, 17US082589/9 and 17US774223/9. Public communication efforts were led by Secretaría de Medio Ambiente y Recursos Naturales (SEMARNAT) with support from the National Marine Mammal Foundation (NMMF) and VaquitaCPR partners. The field operation was funded primarily by the Government of México with complementing funds from the AZA, Global Wildlife Conservation, the Firedoll Foundation, as well as numerous public charities, private organizations, and the general public (see www.vaquitacpr.org).

\section{LITERATURE CITED}

Atkinson S, Dierauf L (2018) Stress and marine mammals. In: Gulland FMD, Dierauf L, Whitman K (eds) CRC handbook of marine mammal medicine, 3rd edn. CRC Press, Boca Raton, FL, p 141-156

Bowkett AE (2009) Recent captive-breeding proposals and the return of the ark concept to global species conservation. Conserv Biol 23:773-776

Braulik GT, Reeves RR, Wang D, Ellis S, Wells RS, Dudgeon D (eds) (2005) Report of the workshop on conservation of the baiji and Yangtze finless porpoise. World Conservation Union, Gland. www.iucn-csg.org

Brownell RL Jr (1976) Status of the cochito, Phocoena sinus, in the Gulf of California. Scientific Consultation on Marine Mammals, Bergen

Butterworth A (ed) (2017) Marine mammal welfare. Animal Welfare, Vol 17. Springer, Cham

CIRVA-5 (2014) Fifth meeting of the Comité Internacional para la Recuperación de la Vaquita. www.iucn-csg.org

CIRVA-7 (2015) Seventh meeting of the Comité Internacional para la Recuperación de la Vaquita. www.iucncsg.org/wp-content/uploads/2010/03/CIRVA-7-FinalReport.pdf

CIRVA-8 (2016) Eighth meeting of the Comité Internacional para la Recuperación de la Vaquita. www.iucn-csg.org/ wp-content/uploads/2010/03/CIRVA-8-Report-Final.pdf

CIRVA-9 (2017) Ninth meeting of the Comité Internacional para la Recuperación de la Vaquita. www.iucn-csg.org/ wp-content/uploads/2010/03/CIRVA-9-FINAL-MAY-2017. pdf

KCowan DF, Curry BE (2008) Histopathology of the alarm reaction in small odontocetes, J Comp Path 139:24-33

Crosta A, Sutherland K (2017) 'Operation fake gold' Los Angeles, CA: elephant action league (EAL): https://elephantleague.org/en (accessed 5 June 2018)

Curry BE, Ralls K, Brownell RL Jr (2013) Prospects for captive breeding of poorly known small cetacean species. Endang Species Res 19:223-243

Eskesen IG, Teilmann J, Geertsen BM, Desportes G and others (2009) Stress level in wild harbour porpoises (Phocoena phocoena) during satellite tagging measured by respiration, heart rate and cortisol. J Mar Biol Assoc UK 89:885-892

Gales N, Waples K (1993) The rehabilitation and release of bottlenose dolphins from Atlantis Marine Park, Western Australia. Aquat Mamm 19:49-59

Goodall J, Maynard T, Hudson G (2009) Hope for animals and their world. Grand Central Publishing, New York, NY

Gulland FMD, Dierauf LA, Whitman KL (eds) (2018) CRC handbook of marine mammal medicine, 3rd edn. CRC Press, Boca Raton, FL

* Hart LB, Wells RS, Kellar N, Balmer BC and others (2015) Adrenal hormones in common bottlenose dolphins (Tursiops truncatus): influential factors and reference intervals. PLOS ONE 10:e0127432

* Harting AL, Johanos TC, Littnan CL (2014) Benefits derived from opportunistic survival-enhancing interventions for the Hawaiian monk seal: the silver BB paradigm. Endang Species Res 25:89-96

*Herráez P, Espinosa de los Monteros A, Fernández A, Edwards JF, Sacchini S, Sierra E (2013) Capture myopathy in live-stranded cetaceans. Vet J 196:181-188

*Hohn AA, Read AJ, Fernandez S, Vidal O, Findley LT (1996) Life history of the vaquita, Phocoena sinus (Phocoenidae, Cetacea). J Zool (Lond) 239:235-251 
Houck M, Lear T, Charter S (2017) Animal cytogenetics. In: Arsham MS, Barch MJ, Lawce HJ (eds) AGT cytogenetics manual, 4th edn. Wiley, New York, NY, p 1005-1013

International Whaling Commission (2018) In: Report of the Scientific Committee. Annex M: report of the Sub-Committee on Small Cetaceans. J Cetacean Res Manag 19(Suppl):1-101

Jaramillo-Legorreta AM, Rojas-Bracho L, Gerrodette T (1999) A new abundance estimate for vaquitas: first step for recovery. Mar Mamm Sci 15:957-973

Jaramillo-Legorreta A, Cardenas-Hinojosa G, Nieto-Garcia E, Rojas-Bracho L and others (2017) Passive acoustic monitoring of the decline of México's critically endangered vaquita. Conserv Biol 31:183-191

* Jefferson TA, Olson PA, Kieckhefer TR, Rojas-Bracho L (2009) Photo-identification of the vaquita (Phocoena sinus): the world's most endangered cetacean. Lat Am J Aquat Mamm 7:53-56

Jiang JP, Downing SE (1990) Catecholamine cardiomyopathy: review and analysis of pathogenic mechanisms. Yale J Biol Med 63:581-591

Kasamatsu M, Hasegawa K, Wakabayashi I, Seko A, Furuta M (2012) Hematology and serum biochemistry values in five captive finless porpoises (Neophocaena phocaenoides). J Vet Med Sci 74:1319-1322

Kastelein RA, Bakker MJ, Dokter T (1990) The medical treatment of 3 stranded harbour porpoises (Phocoena phocoena). Aquat Mamm 15:181-202

Koopman HN, Westgate AJ, Read AJ, Gaskin DE (1995) Blood chemistry of wild harbor porpoises Phocoena phocoena (L.). Mar Mamm Sci 11:123-135

Koopman HN, Westgate AJ, Read AJ (1999) Hematology values of wild harbor porpoises (Phocoena phocoena) from the Bay of Fundy, Canada. Mar Mamm Sci 15:52-64

Martin TG, Nally S, Burbidge AA, Arnall S and others (2012) Acting fast helps avoid extinction. Conserv Lett 5: 274-280

Mei Z, Zhang X, Huang SL, Zhao X and others (2014) The Yangtze finless porpoise: On an accelerating path to extinction? Biol Conserv 172:117-123

Myers M (2015) Sea lions, dolphins still fleet's underwater guardians. Navy Times, 11 April 2015. www.navytimes. com/news/your-navy/2015/04/11/sea-lions-dolphins-stillfleet-s-underwater-guardians/

Neimanis AS, Koopman HN, Westgate AJ, Murison LD, Read AJ (2004) Entrapment of harbour porpoises (Phocoena phocoena) in herring weirs in the Bay of Fundy, Canada. J Cetacean Res Manag 6:7-17

Nielsen NH, Teilmann J, Sveegaard S, Hansen RG, Sinding MHS, Dietz R, Heide-Jørgensen MP (2018) Oceanic movements, site fidelity and deep diving in harbour porpoises from Greenland show limited similarities to animals from the North Sea. Mar Ecol Prog Ser 597:259-272

Norris KS, McFarland WN (1958) A new harbor porpoise of the genus Phocoena from the Gulf of California. J Mammal 39:22-39

Norris KS, Prescott JH (1961) Observations on Pacific cetaceans of California and Mexican waters. Univ Calif Publ Zool 63:291-402

* Norris TA, Littnan CL, Gulland FMD, Baker JD, Harvey JT (2017) An integrated approach for assessing translocation as an effective conservation tool for Hawaiian monk seals. Endang Species Res 32:103-115

Pavin D, Breton HL, Daubert C (1997) Human stress cardiomyopathy mimicking acute myocardial syndrome. Heart 78:509-511

Perrin WF, Myrick AC Jr (eds) (1980) Age determination of toothed whales and sirenians. Rep Int Whaling Comm Spec Issue 3. IWC, Cambridge

Price MRS (1986) The reintroduction of the Arabian oryx Oryx leucoryx into Oman. Int Zoo Yearb 24/25:179-188

Ralls K, Ballou JD (2013) Captive breeding and reintroduction. In: Levin SA (ed) Encyclopedia of biodiversity, Vol 1, 2nd edn. Academic Press, Waltham, MA, p 662-667

Reeves RR, Mead JG (1999) Marine mammals in captivity. In: Twiss J Jr, Reeves RR (eds) Conservation and management of marine mammals. Smithsonian Institution Press, Washington, DC, p 412-436

Renwick DM, Simmons R, Truver SC (1997) Marine mammals are a force multiplier. Proceedings Magazine, Vol 123. US Naval Institute, Annapolis, MD, p 51-56

Rojas-Bracho L, Reeves RR (2013) Vaquitas and gillnets: Mexico's ultimate cetacean conservation challenge. Endang Species Res 21:77-87

Silber GK (1988) Recent sightings of the Gulf of California harbor porpoise, Phocoena sinus. J Mammal 69:430-433

Smith CR, Solano M, Lutmerding BA, Johnson SP and others (2012) Pulmonary ultrasound findings in a bottlenose dolphin Tursiops truncatus population. Dis Aquat Org 101:243-255

St. Aubin DJ, Forney KA, Chivers SJ, Scott MD and others (2013) Hematological, serum, and plasma chemical constituents in pantropical spotted dolphins (Stenella attenuata) following chase, encirclement and tagging. Mar Mamm Sci 29:14-35

Taylor BL, Rojas-Bracho L, Moore J, Jaramillo-Legorreta A and others (2017) Extinction is imminent for Mexico's endemic porpoise unless fishery bycatch is eliminated. Conserv Lett 10:588-595

* Thomas L, Jaramillo-Legorreta A, Cardenas-Hinojosa G, Nieto-Garcia E and others (2017) Last call: Passive acoustic monitoring shows continued rapid decline of critically endangered vaquita. J Acoust Soc Am 142:EL512

van Beest FM, Teilmann J, Dietz R, Galatius A and others (2018) Environmental drivers of harbour porpoise finescale movements. Mar Biol 165:95

Vidal O (1995) Population biology and exploitation of the vaquita, Phocoena sinus. Rep Int Whaling Comm Spec Issue 16:247-272

Wang D (2009) Population status, threats and conservation of the Yangtze finless porpoise. Chin Sci Bull 54: 3473-3484

* Wang D (2015) Progress achieved on natural ex situ conservation of the Yangtze finless porpoise. IUCN-SSC Cetacean Specialist Group. www.iucn-csg.org/index.php/ 2015/12/10/progress-achieved-on-natural-ex-situ-conser vation-of-the-yangtze-finless-porpoise/ (accessed 9 May 2018)

Wells RS, Bassos-Hull K, Norris KS (1998) Experimental return to the wild of two bottlenose dolphins. Mar Mamm Sci 14:51-71

*Wells RS, Fauquier DA, Gulland FMD, Townsend FI, DiGiovanni RA Jr (2013) Evaluating post-intervention survival of free-ranging odontocete cetaceans. Mar Mamm Sci 29:E463-E483

Yu J, Sun Y, Xia Z (2009) The rescue, rehabilitation, and release of a stranded finless porpoise (Neophocaena phocaenoides sunameri) at Bohai Bay of China. Aquat Mamm 35:220-225

Zagzebski KA, Gulland FMD, Haulena M, Lander ME and others (2006) Twenty-five years of rehabilitation of odontocetes stranded in central and northern California, 1977 to 2002. Aquat Mamm 32:334-345 